\title{
Language Learning Strategy Training for Adult English Learners in Continuing Education
}

\author{
ZHU Ya-nan \\ Beijing International Studies University, Beijing, China
}

\begin{abstract}
Strategy training can help learner to become better and independent learners. The four models of language strategy training, namely Pearson and Dole’s model, Oxford et al.'s approach, Chamot and O’Malley's framework, and Cohen' strategies-based instruction (SBI) are discussed and found to have features in common. In the hope of enhancing Chinese adult learners' English learning and helping them become independent and autonomous, the three-stage model is proposed by the writer of the paper. With certain features adopted from the models designed by other researchers, the three-stage strategy training model is suitable to English learners of two-year undergraduate program in continuing education.
\end{abstract}

Keywords: learning strategies, strategy training

\section{Introduction}

Language learning strategies are specific behaviors, techniques, actions, or steps taken by language learners to accomplish a learning goal or to facilitate their own learning. Appropriate and flexible use of language learning strategies can result in greater self-confidence and responsibility, as well as improved proficiency. Language learners are being encouraged to learn "how to learn” a foreign language in recent instructional programs throughout the world. As the Confucian proverb goes, "If you give a man a fish, you feed him for a day; if you teach a man to fish, you feed him for a lifetime”. Besides, according to Oxford (1990a), certain research shows that learners who receive strategy training generally learn better than those who do not. And a large body of research supports the positive effects of training on strategies in language learning performance (Carrell, Pharis, \& Liberto, 1989; Carrell, 1998; Oxford, 1990a; 1990b; Oxford, Crookall, Cohen, Lavine, Nyikos, \& Sutter, 1990). Cottrell (1999) claims that through practice and instruction, learners' use of strategies can be automatized. Therefore, it is necessary for language teachers in continuing education to train their students to use more learning strategies, providing more systematic instruction in learning strategies so that students can choose the strategies that work best for them to meet various learning demands and goals. Language teachers also provide, through strategy training, a way of helping students to become autonomous, i.e., a way of enabling them to take charge of their own learning (Ellis, 1997).

\section{Goals of Learning Strategy Training}

To know about and to make use of language learning strategies are central to the concept of strategic language learning. Through strategy training, language learners can become more aware of the different kinds

ZHU Ya-nan, Master, lecturer, School of English Language, Beijing International Studies University, Beijing, China. 
of possible strategies and select them consciously during their language learning process. And then language learning can be facilitated.

The first goal of strategy training is to explicitly instruct learners about what the learning strategies consist of. Language teachers in continuing education need to help learners to recognize the strategies they already use and then develop a wide set of strategies. Knowing the strategies necessary to be successful language learners is not enough. Being strategic is not only a matter of knowing strategies, but also a matter of knowing how to use them appropriately.

The second goal of strategy training is to specifically teach adult learners in continuing education about how, when, and why language learning strategies can be used to maximize their learning. Both the teacher and learners need to bear in mind that no single strategy is appropriate for all learners or for all learning tasks. Ellis and Sinclair stated (1989, cited in Cohen, 2000, p. 69), "Learner training aims to help learners consider the factors that affect their learning and discover the learning strategies that suit them best”. Strategy training can help individual learners to evaluate their own learning activities and employ various strategies in different contexts in order to meet individual learning demands.

The third goal of strategy training is to develop learner autonomy and self-management. Knowles (1975, cited in Hedge, 2003, p. 83) pointed out that "there is convincing evidence that people who take the initiative in learning learn more things and learn better, than people who sit at the feet of teachers passively waiting to be taught”. Learners are expected to be ultimately capable of making use of the learning strategies appropriately without their teachers' guidance. Learners can monitor, evaluate their performance or the effectiveness of their strategy use, develop their problem-solving skills, and take responsibility for their own learning. Consequently, they can continue learning effectively and independently throughout their lives.

To sum up, through strategy training, the language teachers can raise their students' awareness of learning strategies for more effective learning, help them to develop and strengthen their language learning strategies, and encourage them to become more involved, active, and responsible in their own learning. Strategy training not only helps students to meet their current learning goals, but also develops lifelong learning skills for reaching personal and occupational learning goals.

\section{Models of Learning Strategy Training Designed by Other Researchers}

Considerable research on language learning strategy training has been done. Many researchers such as Pearson and Dole (1987), Oxford (1990a), Oxford et al. (1990), Chamot and O’ Malley (1994), Grenfell and Harris (1999), Cohen (2000) have developed a number of models for strategy training in both first and second language contexts. These instructional models share many features. They agree on the importance of developing students' awareness on the value of learning strategies and suggest that the proper use of learning strategies is facilitated through teacher demonstration and modeling. They emphasize the importance of providing opportunities of practicing the strategies so that students can use them independently. They suggest that students should evaluate how well a strategy has worked, select strategies for a task, and actively transfer strategies to new tasks. In what follows, Pearson and Dole's (1987), Oxford et al.'s (1990), Chamot and O’Malley's (1994), and Cohen's (2000) models are introduced.

\section{Pearson and Dole's Model}

The strategy training model suggested by Pearson and Dole (1987) focuses on first language, but it can 
also be applied to the study of second language. Pearson and Dole's sequence includes:

(1) Modeling for students how to apply the strategy by the teacher, with direct explanation of the strategy's use and importance;

(2) Guided practice with the strategy;

(3) Consolidation where teachers help students to identify the strategy and decide how to apply it;

(4) Independent practice with the strategy;

(5) Application of the strategy to new tasks.

This model aims at isolated strategies. It involves teacher's explicit modeling, direct explanation of how, why, and when a specific strategy ought to be used, and learners' extensive functional practice with the strategy. After that, learners are given chances to apply the strategy to new and different learning tasks. Learners may have better understanding on when and how to use the various strategies if they are first modeled by the teacher and then practiced individually. The teacher can then encourage independent strategy use and develop learner autonomy. Learners are promoted to take more responsibility to select, use, and evaluate the strategies that they have been taught.

\section{Oxford et al.'s Model}

The strategy training model suggested by Oxford et al. (1990) includes seven steps:

(1) The teacher asks learners to do a language task without any strategy training.

(2) Learners discuss how they did it. The teacher comments on the ways in which learners fulfilled the task and identified any helpful strategies which were used by learners.

(3) The teacher suggests and demonstrates other useful strategies.

(4) Learners are given enough time to practice the new strategies with language tasks.

(5) The teacher shows how the strategies can be applied to new tasks.

(6) Learners practice using the strategies to complete other tasks.

(7) The teacher helps learners understand how to evaluate the success of their strategy use and promote them to take more responsibility for their learning.

This model is rather descriptive. It involves students' discussion of their strategy use in a given task to raise their strategy awareness, suggestion of helpful strategies, functional practice with the strategy, self-evaluation or monitoring of the learning process, and demonstration of the transferability of the strategies to other tasks. Learners are given chances to discuss the strategies they employ and they are given more freedom to select the strategies that suit them best and encouraged to self-assess their own language performance.

\section{Chamot and O'Malley's Model}

The strategy training model suggested by Chamot and O’Malley (1994) is very useful for learners who have already practiced using a wide range of strategies in different learning contexts. Chamot and O’Malley's sequence includes:

(1) Planning: Students plan their own approaches to complete a learning task.

(2) Monitoring: Students self-monitor their performance by paying attention to their strategy use and checking comprehension.

(3) Problem-solving: Students find solutions to problems they encounter. 
(4) Evaluation: Students learn to evaluate the effectiveness of a given strategy after it has been applied to a learning task.

This four-step model focuses on helping learners to complete language learning tasks. Each of the four steps helps learners become more conscious about their strategy use, have an opportunity to practice using and transferring the strategies, engage in self-monitoring and evaluation of strategy use, and join in discussions about the rationale behind the strategies. When this training model is used in the classroom, teachers should be encouraged to give suggestive feedback to allow learners to consider alternative ways of completing different learning tasks, and to concentrate on learners' self-valuation of the effectiveness and efficiency of strategy use.

\section{Cohen's Model}

The strategy training model suggested by Cohen (2000), strategies-based instruction (SBI), consists of five steps. The first four steps have often stood alone and can be applied to any kind of language strategy training. It is the last step that distinguishes this model as SBI. According to Cohen, teachers have at least three options to conduct SBI. The first option is that teachers begin with the established course materials and then determine which strategies to insert and where. The second option is that they begin with a set of strategies that they want to focus on and design activities around them. The third option is that they insert strategies spontaneously into the lessons whenever it seems appropriate.

The sequence suggested by Cohen includes:

(1) The teacher describes, models, and gives example of potentially useful strategies;

(2) The teacher elicits additional examples from students based on the students' own learning experiences;

(3) The teacher leads small-group/whole-class discussions about strategies;

(4) Students are encouraged to experiment with a broad range of strategies;

(5) The teacher integrates strategies into everyday class materials, explicitly and implicitly embedding them into the language tasks to provide for contextualized strategy practice.

The strategies-based instruction (SBI) integrates the strategy training into the regular language course content in both explicit and implicit way. It aims to help learners to take more responsibility for their learning and using the second language. It also aims to help them to become more effective learners. In a SBI class, learners get systematic instruction of applying strategies to the learning and use of the target language. Meanwhile, they have chances to share their own preferred strategies with other learners, and to enhance the strategies within the context of the specific language tasks that they are involved.

\section{A Three-Stage Model for Strategy Training of This Paper}

In the preceding sections, four influential strategy training models, are introduced and discussed. According to Cohen (2000, p. 71), "No empirical evidence has yet been provided to determine the best overall method for conducting strategy training”, but at least three aspects of the strategy training have been identified. They have been designed to raise learners' awareness of the purpose and value of strategy use, to give learners chances to practice the strategies they are being taught, and to help them understand how to make use of the strategies in other learning contexts. These three components are necessary for any strategy training approach or model.

Based on the above four models, the suggestions for strategy training by Oxford (1990a), the concept that strategy training should be practical and useful but not abstract or theoretical for learners, a tentative model is 
designed by the writer of this paper for adult English learners in continuing education. This model consists of three stages: pre-training, during-training, and post-training.

Pre-training stage involves the preparation or planning steps in the training model for adult learners.

Step 1: To investigate the adult learners' current learning strategy use.

It is essential for teachers to investigate the strategies that the adult learners have been using and the frequency that they have been employing these strategies. On one hand, the investigation can help teachers to determine the strategies students need to learn or enhance. On the other hand, the investigation can raise students' awareness of different strategies in English learning.

Step 2: To determine the adult learners' factors influencing the strategy use.

The following adult learners' factors need to be taken into account before training: learners' beliefs and attitudes about language learning, learners' age, motivation, personal background, their strengths and weaknesses, their current proficiency level, their expectations concerning the roles of both the teacher and the learner, the reasons why they continue their English learning and etc.

Step 3: To consider the time available for training.

How much time the teacher and learners have available for the training must be taken into consideration. How many hours can be dedicated to the training within a month, even how many minutes within a week should be considered. Whether the training is short-term one or long-term one needs to be determined in advance. Both of them are valuable, but the latter one is likely to be more effective.

Step 4: To choose the strategies for training.

Teachers need to bear the following factors in mind when choosing the strategies for training. First of all, they should choose the strategies that are closely connected with the adult learners' factors or characteristics with the help of the already-done investigation. Secondly, they should identify the strategies that are useful for most learners. Thirdly, they had better select strategies that are transferable to other language learning tasks, in other words, the strategies that are applicable to more learning contexts or language learning skills.

Step 5: To prepare the training materials.

Training materials can be prepared by both teachers and the students. Sometimes it is up to the teacher what kind of materials the students prepare. Sometimes the students can prepare some materials in which they are interested. If so, their motivation may be increased. Textbooks can actually be used as the training materials.

Step 6: To consider integrated strategy training.

As introduced above, Cohen's strategy training model integrates the strategy training into the regular language course. It is assumed to be helpful to integrate strategy training for adult learners in continuing education. When strategy training is closely integrated with regular English learning contents, the learners may well understand how the strategies can be used in a meaningful context (Oxford, 1990a). Wenden (1987) points out the integrated strategy training "enables the learner to perceive the relevance of the task, enhances comprehension, and facilitates retention”.

The second stage of the strategy training model is during-training stage which involves teacher's introduction in the selected strategies, students' practice and evaluation on the strategies.

Step 1: To introduce the selected strategies.

The teacher introduces or informs students as thoroughly as possible the selected strategies. For example, teachers tell their students directly that "getting the idea quickly" is a strategy which is used for listening and 
reading. It helps them concentrate on exactly what they need or want to understand. They can skim for main ideas and scan for specific details.

Step 2: To model the selected strategies.

The students are modeled or demonstrated how to use the strategies properly in specific tasks. Modeling the strategy for students is an essential part of strategy training. Modeling should be done in a task that is similar to the one in which the students will practice the strategy. For example, students may be required to use "inferencing" when listening to an interview. Before having students perform this task, the teacher can model "inferencing" on a similar task, such as listening to a conversation. When listening, the teacher can stop at certain points where s/he does not know certain words or phrases and explains to students that the words or phrases can be figured out through the context, intonation, or other clues.

Step 3: To provide practice.

As the saying goes, "practice makes perfect”. After introducing and modeling the selected strategies, the students are guided to practice the strategies in different English tasks. Take the strategy "organize/plan” for example. After introducing and modeling this learning strategy which is useful when completing an assignment that includes several steps, students are required to make a plan for preparing the dumpling, the traditional meal in China, and describe how to make it. When selecting or creating material for practice, teachers need to bear their students' proficiency level or abilities in mind. They should choose appropriately challenging material and tasks for practice, that is, the material and tasks should not be too easy or too difficult for students. An additional part of practice is teachers' feedback about students' strategy use, which is important in helping students to know how well they use certain strategies.

Step 4: To apply the strategies to new tasks.

The students are encouraged to choose the strategies they will use and apply them to various new English tasks. In other words, they are provided opportunities to transfer the strategies from one task to another. Take the strategy "make predictions" for instance. Students already know that it means making some guesses about what will happen and that predicting information helps them focus their attention. And they are already guided to use prediction before listening to conversations. Students can also use this strategy when watching a movie, listening to news on the radio, or reading a text. It is hoped that students can realize true ownership of their strategies in this application step.

Step 5: To evaluate the strategy use.

The students' evaluation is the last step in this stage. Specifically, they are given time to reflect and summarize their performance, to evaluate the effectiveness of the strategies they use to complete the tasks and to assess their progress. In traditional classrooms, students expect the teacher to evaluate them. With learning strategy training, students begin to take more charge of their own learning and, with guidance from the teacher, to assess their own progress. Students need to find out which learning strategies work best for them for different tasks, why they work, as well as which are not effective, and when and why they are not effective. .

The third stage of the strategy training model is post-training stage. It includes the teachers' evaluation, assessment, and revise on the overall strategy training.

Step 1: To evaluate the strategy training program.

Teachers evaluate the overall strategy training program. Teachers' own observations, during and after the training are also useful for evaluating the success and effectiveness of strategy training. The students' self-evaluation on the strategy use can provide useful data or feedback for teachers. Examples of criteria which 
can be employed for teachers to evaluate the training program are: tasks improvement, general learning skill improvement, maintenance of the new strategies over time, effective and appropriate transfer of strategies to other learning tasks, and improvement in student attitudes toward English learning (Oxford, 1990a).

Step 2: To revise the strategy training program.

Finally, the training program needs to be revised after it has been conducted. The revisions are necessary to ensure the success of the training. The evaluation in Step 1 of this stage provides possible suggestions for the revisions of the training program. And students' suggestions or feedbacks are also important to the revision. This naturally leads back to the first step at first stage of the training program, a reconsideration of the students' strategy use after the cycle of the strategy training. Then a new cycle of strategy training begins.

In essence, the three-stage model for strategy training of this paper is about promoting effective teaching and learning of strategies. This three-stage model is designed to serve as a guide for strategy training program. The first pre-training stage, i.e., the preparation stage, can help teachers make decisions about what is of importance before conducting strategy training; the second stage, i.e., the during-training stage, helps teachers organize and present the strategy training well and students enhance the strategy use; the third stage, i.e., post-training stage, helps teachers improve the training program.

\section{Conclusion}

Taking previous observations and findings into consideration, the writer of the paper points out the goals of strategy training, and puts forward a three-stage strategy training model for English learners in continuing education, based on Pearson and Dole's model, Oxford et al.'s approach, Chamot and O'Malley's framework, and Cohen' strategies-based instruction (SBI). The three-stage model aims to raise adult learners' awareness about the value of learning strategies, give learners chances to practice the strategies that they are being instructed, help them to transfer the strategies to other relevant learning contexts, allow them to reflect their performance, and evaluate the success of the strategy use. The three-stage model concerning strategy training may have certain implications for teachers of two-year undergraduate program in continuing education in general. It is necessary for teachers to "feed their students for a lifetime"-train their students, based on their individual learning styles, current strategy use, and specific goals, to use more learning strategies, providing more systematic instruction in learning strategies so that students can find the methods that work best for them and learn effectively, efficiently, and independently.

\section{References}

Carrell, P. L. (1998). Can reading strategies be successfully taught? Language Teacher 1998. Online.

Carrell, P. L., Pharis, B. G., \& Liberto, J. C. (1989). Metacognitive strategy training for ESL reading. TESOL Quarterly, 23, 647-678.

Cottrell, S. (1999). The study skills handbook. London: Macmillan Press.

Chamot, A., \& O’Malley, J. (1994). The CALLA handbook: Implementing the cognitive academic language learning approach. New York: Addision-Wesley.

Cohen, A. D. (2000). Strategies in learning and using a second language. Beijing: Foreign Language Teaching and Research Press.

Ellis, R. (1997). Second language acquisition. Oxford: Oxford University Press.

Grenfell, M., \& Harris, V. (1999). Modern languages and learning strategies-in theory and practice. London: Routledge.

Hedge, T. (2003). Teaching and learning in the language classroom. Shanghai: Shanghai Foreign Language Education Press.

Oxford, R. (1990a). Language learning strategies: What every teacher should know. New York: Newbury House. 
Oxford, R. (1990b). Styles, strategies, and aptitude: Connections for language learning. In T. S. Parry and C. W. Standsfield (Eds.), Language aptitude reconsidered (pp. 67-125). Englewood Cliffs: Prentice Hall Regents.

Oxford, R., Crookall, D., Cohen, A., Lavine, R., Nyikos, M., \& Sutter, W. (1990). Strategy training for language learners: Six situational case studies and a training model. Foreign Language Annals, 22, 197-216.

Pearson, P. D., \& Dole, J. A. (1987). Explicit comprehension instruction: A review of research and a new conceptualization of learning. Elementary School Journal, 88, 151-165.

Wenden, A. (1987). Incorporating learner training in the classroom. In A. Wenden and J. Rubin (Eds.), Learner strategies in language learning (pp. 159-168). Englewood Cliffs, N.J.: Prentice Hall. 